experimenting with wireless telegraphy, using coherers and magnetic detectors. In 1899, Sir Ambrose was appointed scientific advisor to the Marconi Company, and soon came up against the problem of finding a more stable detector, suitable for operating a morse printer. In November 1904, he removed from the cupboard the rectifying valve, set up a high-frequency generator on the lecture bench, and was successful in using for the first time a thermionic valve detector of electromagnetic radiation. Very soon, special valves were being designed for this purpose. The cabinet of valves, occupying a prominent position in the College Engineering Department, will be a constant reminder of Sir Ambrose Fleming and of the rapid developments during the last thirty-five years.

\section{Million-Volt X-Ray Tube}

A PAPER on a million-volt X-ray tube which has been installed and is in operation for treatment at St. Bartholomew's Hospital was read before the Institution of Electrical Engineers by Allibone, Bancroft and Innes at a meeting held on April 13. A description was given of the design, equipment, lay-out and operation of the unit. Briefly, it may be said that the tube embodies the principles of the all-metal X-ray tube designed by Dr. Allibone for lower voltages, and the elaboration set out in the present paper arises from the scale of voltages used. The X-ray tube consists of a .steel tube 14 in. in diameter and $17 \mathrm{ft}$. long; the central portion of it, from which the $\mathrm{X}$-ray beam emerges, traverses the treatment room and projects into each generator room. The generator rooms each house $500 \mathrm{kv}$. D.c. generators. The X-ray tube and thermionic rectifiers used in the D.C. generators are evacuated continuously by oil diffusion pumps, and the whole apparatus is readily demountable. Removable filament assemblies are fitted to the rectifiers and facilitate rapid replacement of filaments; a special cathode with six interchangeable filaments has been developed for the $\mathrm{X}$-ray tube to avoid frequent admission of air into the tube during filament replacements. The tube is now used continuously at $1000 \mathrm{kv}$. and has been operated experimentally at $1100 \mathrm{kv}$. Curves relating $\mathrm{X}$-ray output with voltage and filtration by metallic filters are given, and a radiograph is included to illustrate the capabilities of the tube if applied to industrial radiography.

\section{Revised Broadcasting Wave-Lengths}

AFTER sitting for some six and a half weeks during March and April at Montreux, the international broadcasting conference has terminated with the issue of a plan for the revision of the wave-lengths and power of broadcasting stations in the European zone, which includes Iceland and the Mediterranean basin. The 'Montreux Convention', as it is known in broadcasting circles, was signed by the representatives of thirty-one States, and provides for certain changes in wave-length and power of European broadcasting stations to come into effect on March 4,
1940. The changes to be made affect all the British stations, including those at Start Point, Clevedon and Norwich, which are not yet in regular operation. Details of the changes indicating the manner in which they may affect British listeners to broadcasting were outlined in recent issues of The Times and the Wireless World. Power limitations have been imposed by the Convention, varying from $500 \mathrm{kw}$. for long-wave stations by day only to $10 \mathrm{kw}$. for stations operating on the shortest wavelengths of the medium wave-band. Although Great Britain has been allocated the exclusive use of only three wave-lengths, it is pointed out that our geographical position on the outer fringes of Europe is such that we can share wave-lengths with other countries in a way that would be impracticable in central Europe. Generally speaking, it may be said that the plan provides an improved state of affairs in the long-wave band, and also in the middle-wave band so far as home reception is concerned. In view of the developments of broadcasting, and the increase in number and power of stations during recent years, the Montreux Conference would appear to have achieved a satisfactory result if it has succeeded in avoiding any deterioration in the service now provided in all countries.

\section{Further Extension of the Ashmolean Museum, Oxford}

A Further extension of the Ashmolean Museum in the University of Oxford was opened by Lord Crawford and Balcarres on April 25, towards the cost of which the Worshipful Company of Drapers has contributed the sum of $£ 10,000$. The Master of the Company, Sir Auston Harris, in the course of his remarks at the opening ceremony, said that while the City Companies can no longer vie with the munificent gifts of wealthy Englishmen, or with great American corporations, this gift would serve as another mark of the respect and esteem which an ancient City Company bears towards an ancient University. The extension is on the north-east corner of the building, and provides for the Museum's Egyptian collections, which it has now been possible to arrange in chronological order, a lecture room, and a storage basement. A set of smaller rooms on six floors has been built between the new wing and the Taylorian Institution. Here are students' workrooms, a room for the keeper, Mr. E. T. Leeds, and rooms for the preparation of exhibits. This is the third extension added to the buildings in five years, and marks the final stage in the plans for the enlargement of the accommodation to relieve pressure on the Museum's space. The first extension was the provision of the Weldon Gallery in 1934, and the second was the addition of the Griffith Institute, which was opened in January last. The gallery in which the Egyptian collections were formerly housed has now been divided by screens into three rooms, to be devoted respectively to the European prehistoric period, covering the stone and bronze ages, the Minoan collection, by the gifts of Sir Arthur Evans now the finest in existence, and the Near Eastern Collections. 